\title{
The Application Analysis and Risk Prevention in Rapid Development of Exchangeable Bonds
}

\author{
Ping Huang \\ Shanghai University
}

\begin{abstract}
The exchange bones have been rapidly developed since 2016, and plays an increasingly significant role in China's financial market. In this paper, the concept and main characteristics of exchangeable bonds were introduced, and the exchangeable bonds issued from 2013 to the first quarter of 2018 in China were also analyzed. Moreover, through the study of several classical cases to explore the better use of exchangeable bonds, this paper also analyzes the risk of exchangeable bonds in market and puts forward some Suggestions. The results obtained show that for the risks prevention of exchangeable bonds, the supervision of exchangeable bonds should be strengthened, the awareness of risks among issuers and investors should be raised, in addition, more in-depth researches on the terms of exchangeable bonds should be conducted, and other types of financial instruments should be combined with the exchangeable bonds to hedge the risks involved.
\end{abstract}

Keywords-Exchangeable bond; Risk prevention; Major shareholder reduction

\section{INTRODUCTION}

Exchangeable bonds (hereinafter referred to as EB) are known as "exchangeable bonds of other companies", a compound derivative. The issuer of EB issues corporate bonds by mortgages of the shares they hold, and the bond holders can use the EB held in exchange for the shares of the listed company that the issuer has pledged in accordance with the conditions agreed upon at the time of issuance.

It can be considered EB as a convertible bond. The main difference between them is that the convertible issuer of the convertible bonds is the listed company itself. After exercising the rights, the total share capital of the listed company will increase, and the EB can be the major shareholder of the listed company. After the exercise of the rights, the total share capital of the listed company will not increase total share capital.

The issuer of exchangeable bonds must agree to repay the outstanding exchangeable bonds at maturity in the future, so as long as the investor holds maturity and does not convert, the EBs are no different from ordinary bonds. If the holder finds profitable conversions during the conversion period, the holder may choose to replace the EBs with stocks pledged by the issuer. To some extent, it is equivalent to adding an option to the bond, and the price of the EB and whether the holder will choose to exchange shares depends largely on the price of the pledged shares.

The terms of the EB are relatively complex and flexible, not only the core terms such as the coupon rate and the maturity of the bonds, but also the conversion price, the conversion time, the downward revision clause, the return sale terms, and the conditions. Redemption clauses and other additional terms, the setting of these terms is very flexible, the issuer can set the above terms through their own needs.

Through the design of different terms, the EBs can be used in various fields, including financing, reduction of holdings, equity adjustments, mergers and acquisitions, and market value management. Financing through different methods will have a significant impact on the company's costs [1]. Table 1 lists the differences in centralized financing methods.

TABLE I. COMPARISON OF VARIOUS FINANCING METHODS.

\begin{tabular}{|c|c|c|c|c|}
\hline & EB (financing type) & EB (reduction type) & $\begin{array}{c}\text { Equity pledge } \\
\text { financing }\end{array}$ & $\begin{array}{c}\text { Reduction of bulk } \\
\text { transactions }\end{array}$ \\
\hline capital cost & above $4 \%$ & above $4 \%$ & About $7 \%$ & None \\
\hline Bond maturity & $1-6$ years & $1-6$ year & $\begin{array}{c}\text { Usually less than } 2 \\
\text { years }\end{array}$ & The current holdings \\
\hline Transaction target & Tradable shares & Tradable shares & Restricted stock & Shares outstanding \\
\hline
\end{tabular}




\section{CHINA'S EBS SUPERVISION AND DEVELOPMENT}

A. The main difference between public offerings EBs and private placements $E B$ s
China's current EBs can be divided into publicly offering EBs and private placements EBs according to different ways of issuance. There are large differences in terms of approval and issuance thresholds. Table 2 lists some of the major differences.

TABLE II. PUBLIC OFFERING OF EB AND PRIVATE PLACEMENTS EB

\begin{tabular}{|c|c|c|}
\hline & Public offerings EBs & Private placements EBs \\
\hline Approval & $\begin{array}{c}\text { Pre-examined by the exchange, approved by } \\
\text { the CSRC }\end{array}$ & Pre-examination by the exchange \\
\hline The main threshold & $\begin{array}{l}\text { Net assets no less than } 300 \text { million yuan; } \\
\text { Post-issuance bond balance does not exceed } \\
40 \% \text { of net assets; } \\
\text { Net assets of the underlying stocks shall not } \\
\text { be less than RMB } 1.5 \text { billion or the weighted } \\
\text { average return on equity of the last three } \\
\text { years shall not be less than } 6 \% \text { on average; } \\
\text { no restrictions on sales of stocks or other } \\
\text { conflicts with exchanges }\end{array}$ & $\begin{array}{l}\text { There are no restrictions on the sale of } \\
\text { shares or other exchange conflicts during } \\
\text { the conversion period; } \\
\text { there are no other restrictions on the rights } \\
\text { that are subject to judicial freezing }\end{array}$ \\
\hline $\begin{array}{l}\text { Guarantee/Rating } \\
\text { Requirements }\end{array}$ & $\begin{array}{l}\text { Pledged by stocks, the EBs must be rated by } \\
\text { a credit rating agency }\end{array}$ & Pledged by stock, no rating required \\
\hline Term & In $1-6$ years & 2-3 years \\
\hline $\begin{array}{l}\text { Conversion, } \\
\text { Redemption, } \\
\text { Recycling Clause } \\
\text { Requirements }\end{array}$ & $\begin{array}{l}\text { It can be converted after } 1 \text { year. Redemption } \\
\text { and return sale terms can be set. }\end{array}$ & $\begin{array}{l}\text { It can be converted after } 6 \text { months, } \\
\text { redemption and return sale terms can be set. }\end{array}$ \\
\hline Circulation / Trading & $\begin{array}{l}\text { Full price of Shenzhen Stock Exchange, net } \\
\text { price of Shanghai Stock Exchange }\end{array}$ & Listing transfer \\
\hline
\end{tabular}

\section{B. Exchangeable bonds issue status}

EBs have a longer issuance period, lower financing costs, and larger financing amounts. According to the Wind statistics, the EBs issued in 2013- the first quarter of 2018 are based on the view that most of the current EBs issued are medium and long-term, with an average of 2.91 years and a maximum of 6 years, which is comparable to bank credit. From the perspective of financing size, it can reach a maximum of 20 billion yuan, with an average value of 1.252 billion yuan. Table 3 shows the basic situation of the exchangeable bonds issued since 2013- the end of the first quarter of 2018.

TABLE III. DESCRIPTIVE STATISTICS OF EXCHANGEABLE BONDS

\begin{tabular}{|c|c|c|c|c|c|}
\hline & Maximum & Median & Minimum & Mean & Standard deviation \\
\hline Years & 6.00 & 3.00 & 1.00 & 2.91 & 0.94 \\
\hline Coupon rate (\%) & 10.00 & 3.00 & 0.10 & 3.49 & 2.45 \\
\hline $\begin{array}{c}\text { Amount (hundred } \\
\text { million yuan) }\end{array}$ & 200.00 & 6.00 & 0.30 & 12.52 & 23.18 \\
\hline
\end{tabular}




\section{THE APPLICATION OF EBS IN CHINA'S FINANCIAL MARKETS AND CLASSIC CASES}

\section{A. Financing}

Financing is one of the core functions of EBs. If the issuer issues the main purpose of the EBs is financing, the issuer will often set looser redemption terms in order to redeem the bonds before the holders convert their shares. In order to "compensate" investors for losses that cannot be exchanged, such exchangeable interest rates are relatively higher than those that are biased towards reductions. The benefits of financing with EBs are obvious, because the EBs are not only lower in interest rate than ordinary bonds but also easier to issue than ordinary bonds. In recent years, investors in the market have recognized the EBs, and it is relatively easy to find the buyers in the market for the exchangeable bonds. For example, 14 Haining EB has set a higher issuance premium rate, higher coupon interest, and the absence of setting down the terms and setting the redemption terms before the swap period all indicate that the issuer's willingness to convert shares is very weak. This case is a classic example of an issuer's simple financing through the use of exchangeable bonds.

\section{B. Stock reduction}

EBs can be used for premium reductions. Compared to direct reductions from the stock market, EBs can reduce the impact on the stock market, and can obtain a certain premium, while the reduction in the stock market may cause the stock price to fluctuate, affect the reputation of the company, and bear the loss of discounted sales. For the restricted shares, since the EBs only require the stocks to be unrestricted during the conversion period, the stocks in the restricted period can be cashed in advance through the EBs. For example, after the "shares disaster" occurred in China's A-share market in 2015, Zhengbang Group promised not to reduce its holdings in the stock market within the next six months. This commitment expires on January 8, 2016. However, Zhengbang Group issued a private placement bond on November 23, 2015, obtained funds in advance, and successfully converted shares during the conversion period.

\section{Mergers and acquisitions}

EBs has played a huge role in financing. In 2016, Apex's remarkable acquisition of US printer giant Lexmark International, Apex's controlling shareholder Senna Technology raised RMB 6 billion through EBs. Mergers and acquisitions of Lexmark International provide an important source of funding.

\section{Portfolio arbitrage}

EBs can be combined with other financial instruments to achieve arbitrage [2]. One is that the controlling shareholder of the issuer will carry out the arbitrage by increasing or issuing convertible bonds. For example, on December 25, 2015, Meike Households issued private placements to major shareholders at a price of 10.72 yuan per share. Meike Group issued $15 \mathrm{~EB}$ and $16 \mathrm{~EB}$ in 2015 and 2016. The initial conversion price was 20 yuan and 22 yuan, respectively, and the financing rates were $4.5 \%$ and $4.3 \%$. There is an opportunity for arbitrage in the middle of the difference of nearly 10 yuan. The major shareholders will issue additional shares at low prices, and then they will apply for issuance of EBs at the time of the stock's high position, and will recover the funds for targeted additional issuance to obtain the intermediate spread profit. Since the controlling shareholder usually owns the controlling power of the listed company, the knowledge of the listed company is obviously higher than that of the external investor. It may even control the stock price through certain means. For example, according to the media management hypothesis [3], major shareholders of listed companies can publish favorable news in the media, raising stock prices and achieving reductions.

This means of increasing through discounts is considered to be the behavior of interest transfers under the control of large shareholders [4].

Another arbitrage strategy is to reduce holdings of highpriced EBs and to increase holdings of low-price convertible bonds. Geer Group adopts such a tactic. First, it issued a total of 1.2 billions yuan worth of $\mathrm{EBs}$ at a price of 28.50 yuan/share. Other geer shares issued convertible bonds at a price of RMB 24.23 per share, and the majority shareholder geer Group subscribed for approximately RMB 1.05 billion in convertible bonds. As the controlling shareholder has a preemptive right for the convertible bonds issued by the listed company, if the convertible bonds subscribed by the major shareholders and the exchangeable bonds issued are of equal size, the arbitrage between the convertible bonds and the EBs can be carried out.

\section{RISK PREVENTION UNDER EXPLOSIVE DEVELOPMENT OF EB}

\section{A. EB can be risky}

Although the default risk of exchangeable bonds is relatively offset, it cannot be ignored. On the one hand, the EBs have no mandatory rating on the company, and investors have certain difficulties in judging the risk of the bond. On the other hand, the price of stocks with pledged EBs fluctuates greatly. When the stock market fluctuates violently and prices fall sharply, it may cause losses to investors. As for the issuer, the sluggish share price may trigger the terms of the sale, which will have a huge impact on the liquidity of the company

The authenticity of the issuer's purpose of issuing exchangeable bonds is doubtful. [5] Since the issuer is usually a major shareholder of a listed company, the level of understanding and control of the listed company is far greater than that of small and medium investors. Major shareholders 
and listed companies may obtain profits through the arbitrage combination mentioned in section 3. To a certain extent, it infringes the interests of small and medium investors and EB investors in listed companies.

The EBs that are biased to exchange shares have revealed to some extent the signal of reduction by major shareholders, which may adversely affect the stock price of the underlying stocks. When the stocks fall, they will have an adverse effect on the EBs. In order to make the conversion smoothly, the issuer will set down the stock price revision clause. If the stock price drops to a certain extent, the issuer needs to correct the conversion price. This may cause some damage to the issuer. Another very large risk of falling share prices is the punishment of the repurchase terms, which means that the issuer needs to buy back the issued bonds in advance. This not only does the purpose of the issuer reduce the shares but also the liquidity affects of the company.

The terms of the EBs are complex and investors may not be able to identify the hidden risks therein, resulting in situations where accepting a very low coupon rate eventually fails to convert shares. Both issuers and investors may have caused unexpected losses due to the unreasonable setting of the bond terms.

As a relatively new bond, the EBs have a relatively lax regulatory policy. In addition to complicated terms, the regulatory agencies are unable to perform their functions well and generate greater risks. Some companies may bypass regulations through various means and infringe on the interests of investors.

\section{B. Exchangeable bond risk prevention}

Enhance investors' awareness of risk prevention. Investors should correctly recognize the risks of EBs and increase their research on EBs. Although many of the EBs have not been rated, investors can still use the bonds or other channels issued by the company in the past or even rely on third-party agencies to strengthen the risk awareness of the issuer's entity and bonds.6]

Improve the information disclosure system and pay attention to the true purpose of EBs. To verify the issuer's issuance purpose and avoid the issuer's infringement of the interests of other investors through the issuance of the EBs. At the same time, the issuer's supervision in the secondary market should be strengthened and zero tolerance for the manipulation of stock prices should be tolerated. It is necessary to strictly investigate violations of relevant companies and responsible persons and restrict their behavior through legal and administrative penalties. Infringement of stakeholders should also be investigated for civil liability.

Because of the special nature of exchangeable bonds, in addition to the issuer, the companies whose stocks have been converted should also be given special attention. An assessment of the underlying stocks that can be paid should be made, including the industry cycle, profitability, and the impact of exchangeable bonds on the stock price of the company in which the stock is being held. If the exchanged stock company suffers from problems such as poor management, it will affect the stock price of the company, and ultimately it will also affect the exchangeable bonds, posing great risks to them. Therefore, we should study the financial status and operating conditions of the two companies at the same time.

Investors should carefully study the terms of the EBs, compare the commonly used terms in the market, and understand the risks that the exchange of special terms may bring to the bonds. The terms of EBs are complex, but they are not unlawful. Most of the terms should be judged based on past experience. For some of the less common terms, special studies can be conducted to judge the risks based on typical cases. At the same time, we must pay attention to the combination of terms. Some articles can be used in conjunction with other financial instruments issued by the company. Investors can't just focus on the exchangeable bonds. They should also pay attention to other financial instruments recently issued by the company and its related parties to determine the risks involved.

Strong supervision. Regulators should improve the regulatory system for exchangeable bonds, and they should not ignore the verification of substantive elements, especially the issuer's qualifications, use of funds, and the review of bond terms. At the same time, the issuer is required to strictly perform its own obligations. The relevant intermediary agency should perform due diligence and there should be no fraud. The laws and regulations should be strictly followed, and related work should be carried out according to the content of the prospectus.

\section{CONCLUSION}

From the study of this article, we can see that EBs can enrich China's financial products. Both the issuers and bond investors can pray for good results. The EB can realize his various functions through complicated clause design, but at the same time, because of these complicated clauses, it may hide many risks. But this kind of risk can be reduced by various means. This risk prevention should be carried out from different perspectives and at different levels. From the perspective of policy designers, the development of the exchangeable bonds should be well planned, and the lack of institutions should not destroy it. From a regulatory point of view, supervisory agencies should perform their duties well and strictly restrict the behavior of all parties so that they are legally compliant. From the perspective of the issuer, it is necessary to understand the role of the exchangeable bonds for themselves, so that the exchangeable bonds can serve the company's operations, and it should also fulfill its own responsibilities. Things that are promised to themselves should be done, and obligations to themselves should be completed. The risks that may be borne by itself should be fully researched and related measures should be taken. For investors, it is necessary to strengthen the understanding of the exchangeable bonds and identify the risks involved. The exchangeable market in China is still evolving, and the use of exchangeable products is also constantly enriched. The risks that exist in them are extremely guarded against and should be taken seriously. 


\section{REFERENCES}

[1] Martynova M, Renneboog L. What determines the financing decision in corporate takeovers: Cost of capital, agency problems, or the means of payment?[J]. Journal of Corporate Finance, 2009, 15(3):290-315.

[2] Lee C F, Lee $\mathrm{K} \mathrm{W}$, Yeo H H. Investor protection and convertible debt design [J]. Journal of Banking \& Finance, 2009, 33(6):985-995

[3] Ahern K R, Sosyura D. Who Writes the News? Corporate Press Releases during Merger Negotiations [J]. Journal of Finance, 2014, 69(1):241291

[4] Baek J S, Kang J K, Lee I. Business Groups and Tunneling: Evidence from Private Securities Offerings by Korean Chaebols [J]. Journal of Finance, 2006, 61(5):2415-2449.

[5] Zhou Yun, Wen Lirong. The risk prevention in the background of the blowout development of private equity exchange $[\mathrm{J}]$. Wuhan Finance, 2017(07):17-22.

[6] Pan Ailing, Qiu Jinlong, Liu Wenkai. The Application of Exchangeable Bonds in Mergers and Acquisition: Driving Factors, Derivative Risk and Risk-control Mechanism [J]. Research on Economics and Management, 2017, 38(06):137-144. 